\title{
Successful Treatment of Cardiac Angiosarcoma Associated with Disseminated Intravascular Coagulation with Nab-Paclitaxel: A Case Report and Review of the Literature
}

\author{
Kazunori Honda Masashi Ando Keiji Sugiyama Seiichiro Mitani \\ Toshiki Masuishi Yukiya Narita Hiroya Taniguchi Shigenori Kadowaki \\ Takashi Ura Kei Muro \\ Department of Clinical Oncology, Aichi Cancer Center Hospital, Nagoya, Japan
}

\section{Keywords}

Angiosarcoma $\cdot$ Heart · Disseminated intravascular coagulation $\cdot$ Kasabach-Merritt

phenomenon $\cdot$ Nab-paclitaxel

\begin{abstract}
Angiosarcoma of the heart is an uncommon soft tissue sarcoma. A few cases of disseminated intravascular coagulation (DIC) associated with angiosarcoma occurring in various organs, but not the heart, have been reported. Although taxane is commonly used in the treatment of metastatic angiosarcoma, data on the efficacy of nab-paclitaxel for angiosarcoma are limited. Here, we report probably the first case of a patient with primary cardiac angiosarcoma with coexisting DIC who was successfully treated with nab-paclitaxel. A 62-year-old female with chief complaints of nausea and shortness of breath was diagnosed as having cardiac
\end{abstract}




\section{Case Reports in Oncology}

angiosarcoma with liver metastases. Four months after the resection of her primary tumor, the hepatic metastatic lesions progressed rapidly accompanied by new metastatic lesions in the right iliac bone and signs of DIC. She received nab-paclitaxel as first-line chemotherapy. A response of stable disease was achieved after 2 treatment cycles and DIC was successfully controlled for at least 4 months. This report suggests potential utility of nab-paclitaxel for angiosarcoma complicated with DIC. We also review the literature for all cases of angiosarcoma with DIC reported so far.

\section{Introduction}

Angiosarcoma is a rare malignancy of endothelial origin, accounting for about $2-4 \%$ of all soft tissue sarcomas [1]. Angiosarcomas can originate in any part of the body such as the skin, viscera, and soft tissue. In a pooled data analysis involving 534 patients, the prevalence of angiosarcoma was $27.0 \%$ in the head and neck, $19.7 \%$ in the breast, $15.3 \%$ in extremities, $9.5 \%$ in the trunk, $6.0 \%$ in the liver, and $4.7 \%$ in the heart [1]. Cardiac angiosarcoma typically occurs in the right atrium and is usually advanced at presentation. Cardiac angiosarcoma is often overlooked as an initial diagnosis because of its rarity and lack of specific symptoms.

There have been a few reported cases of angiosarcoma with coagulation abnormalities including disseminated intravascular coagulation (DIC) [2-17]. In one report, 7 (16.7\%) of 42 patients who had angiosarcoma were diagnosed as having DIC [2]. Thus, DIC is not an uncommon complication associated with angiosarcoma and offers a challenge to angiosarcoma treatment.

Anthracyclines, ifosfamide, and taxanes are used to treat metastatic angiosarcoma [1]. In contrast to other soft tissue sarcomas, angiosarcomas are particularly responsive to taxanes, especially paclitaxel [1]. Although 2 case reports regarding the use of nab-paclitaxel for treating angiosarcoma are available, there is no report on successful treatment of angiosarcoma complicated with DIC $[18,19]$. Nab-paclitaxel is nanoparticle albumin-bound paclitaxel and is approved for the treatment of breast cancer, gastric cancer, non-small cell lung cancer, and pancreatic cancer in Japan.

Here, we report a rare case of an advanced primary cardiac angiosarcoma associated with DIC who was successfully treated with nab-paclitaxel.

\section{Case Presentation}

A 62-year-old woman presented to her primary physician with complaints of nausea for 3 days. Radiographic evaluation revealed a tumor of $6 \mathrm{~cm}$ in the right atrium and multiple liver metastases. She already had symptoms of heart failure, such as shortness of breath, at presentation. Resection of the primary tumor was performed urgently on the next day of her first visit. The tumor was located in the right atrium and invaded the superior vena cava and right ventricle. The resection margin was positive. Histological examination showed several vascular lumens surrounded by round or spindle tumor cells. Immunohistochemistry revealed CD34 positive, CD31 positive, FVIIIa positive, S-100 negative, and a Ki-67 index of 


\section{Case Reports in Oncology}

Case Rep Oncol 2017;10:863-870

DOI: $10.1159 / 000481194$

(C) 2017 The Author(s). Published by S. Karger AG, Basel www.karger.com/cro

Honda et al: Successful Treatment of Cardiac Angiosarcoma Associated with

Disseminated Intravascular Coagulation with Nab-Paclitaxel

$10 \%$, corresponding to angiosarcoma. TNM staging was T2N0M1, but no additional treatment (such as chemotherapy) was performed for reasons not clearly known. She presented with right proximal leg pain 4 months after surgery, and CT scan revealed rapid progression of multiple liver metastases well enhanced by contrast as well as multiple metastases to the right ilium (Fig. 1a).

She was referred to our hospital immediately after confirmation of disease progression. She had no family history of malignancy. She had never smoked and was allergic to alcohol. Physical examination showed no abnormalities except for multiple hemorrhagic macules at extremities. Blood test showed coagulation abnormalities (platelets $8.7 \times 10^{4} / \mu \mathrm{l}$, a low fibrinogen level of $89.3 \mathrm{mg} / \mathrm{dL}$, prolonged prothrombin and activated partial thromboplastin time of $65.7 \%$ and $40.5 \mathrm{~s}$, respectively) and high levels of fibrin degradation products (203.6 $\mu \mathrm{g} / \mathrm{mL})$ and D-dimer $(110.3 \mu \mathrm{g} / \mathrm{mL})$. Based on these data, we diagnosed her condition as DIC associated with angiosarcoma. She was admitted immediately and received fresh-frozen plasma and recombinant thrombomodulin- $\alpha$. Recombinant thrombomodulin- $\alpha$ was used for 6 days in order to reduce the consumption of coagulation factors induced by thrombosis. Nab-paclitaxel was started on the next day at a dose of $100 \mathrm{mg} / \mathrm{m}^{2}$ as a 3 weeks on/1 week off regimen. We selected nab-paclitaxel instead of paclitaxel because paclitaxel contains alcohol and the patient was allergic to alcohol. Coagulation abnormalities improved shortly after the initiation of chemotherapy (Fig. 2). She was discharged on day 11 after starting nab-paclitaxel. After 2 cycles of nab-paclitaxel, CT scan showed shrinkage in tumor size by around $9 \%$ with appreciable decrease in enhancement among the multiple liver metastases (Fig. 1b). There was no relapse of DIC and no evidence of local recurrence despite positive surgical margin. Response evaluation according to Response Evaluation Criteria in Solid Tumor version 1.1 was stable disease. Adverse events were relatively mild, except for cumulative sensory peripheral neuropathy up to grade 2 according to Common Terminology Criteria for Adverse Events version 4.0. Currently, 4 months after the initial chemotherapy, the patient is continuing to receive nab-paclitaxel at our outpatient chemotherapy center without disease progression and relapse of DIC. She is currently on her 6th cycle of nabpaclitaxel.

\section{Discussion}

To our knowledge, this is the first report of a patient with cardiac angiosarcoma with DIC who was successfully treated with nab-paclitaxel. Primary angiosarcoma of the heart is an uncommon tumor; however, angiosarcoma is the most common histologic subtype among all cardiac sarcomas.

DIC is often observed as a complication of advanced disease in several malignancies. Advanced angiosarcoma is more frequently associated with coagulation disorders than other sarcomas [2], although the reasons for this association are unclear. One possible hypothesis for this association could be the Kasabach-Merritt phenomenon (KMP). The KMP is a lifethreatening complication occurring in approximately $70 \%$ of cases of kaposiform hemangioendothelioma and $10 \%$ of tufted angioma, and is characterized by severe thrombocytopenia and consumption coagulation abnormality such as DIC $[20,21]$. However, the term KMP has 


\section{Case Reports in Oncology}

Case Rep Oncol 2017;10:863-870

DOI: $10.1159 / 000481194$

(C) 2017 The Author(s). Published by S. Karger AG, Basel www.karger.com/cro

Honda et al.: Successful Treatment of Cardiac Angiosarcoma Associated with

Disseminated Intravascular Coagulation with Nab-Paclitaxel

recently been used indiscriminately to describe thrombocytopenia or coagulation abnormalities associated with any vascular anomaly.

Anthracyclines, ifosfamide, and taxanes are the standard cytotoxics used to treat metastatic angiosarcoma [1]. In addition, several molecular targeted agents, including bevacizumab, sunitinib, and sorafenib, have shown potential efficacy in the treatment of angiosarcoma [1]. However, the experience with the use of molecular targeted agents among patients with DIC is limited because these are newer agents that have only been recently available. These targeted drugs are also usually contraindicated in DIC because of their propensity to cause bleeding or thrombosis due to the inhibition of the antivascular endothelial growth factor/antivascular endothelial growth factor receptor axis. So far, to the best of our knowledge, there are only 2 case reports of treatment with nab-paclitaxel in patients with angiosarcoma; both without associated DIC $[18,19]$. In a report by Hara et al. [18], remarkable regression was achieved in a patient with recurrent angiosarcoma of the chest wall after first-line nab-paclitaxel therapy, and the disease was well controlled for a relatively long period. In a report by Olawaiye et al. [19], a patient with angiosarcoma of the uterus experienced complete disappearance of ascites following surgery after having received 6 cycles of nab-paclitaxel and bevacizumab as second-line treatment.

Our literature search identified 22 cases of angiosarcoma associated with coagulation abnormalities reported so far in various primary organs (Table 1) [2-17]. The median age was 67 years (range, 28-87) and 12 patients $(55 \%)$ were male. The sites of primary tumor were the scalp $(n=6,27 \%)$, liver $(n=6,27 \%)$, breast $(n=5,23 \%)$, heart $(n=1,5 \%)$ and others $(n=4,18 \%)$. There was only 1 case with primary cardiac angiosarcoma [2]. The patient was a 54-year-old female with multiple metastases to the lung, pleura, bones, and bone marrows. She received doxorubicin plus ifosfamide, and DIC was temporarily resolved. However, she died 6 months after her first presentation. Several other patients with angiosarcoma-associated coagulopathy were successfully treated by resection, radiotherapy, or chemotherapy. However, most cases had poor survival of less than 1 year after any type of treatment. Only 1 patient received nab-paclitaxel as fourth-line treatment; however, efficacy was not reported [2]. This patient was a 42-year-old female with primary angiosarcoma in the breast that had metastasized to the chest wall, ribs, and lung. She underwent mastectomy for the treatment of localized disease and received 6 cycles of gemcitabine plus docetaxel followed by radiation as adjuvant therapy. She developed relapse within 11 months after surgery and received various treatments including liposomal doxorubicin plus carboplatin, sirolimus, pazopanib, nab-paclitaxel, bevacizumab, and vinorelbine. She died 11 months after the diagnosis of recurrence.

To the best of our knowledge, our report is the first case in the literature describing successful treatment of angiosarcoma complicated with DIC with nab-paclitaxel. However, our report is a case report of a single patient and further studies are necessary to evaluate the true efficacy of nab-paclitaxel in angiosarcoma complicated with DIC.

In conclusion, we report for the first time a case of primary cardiac angiosarcoma complicated with DIC who achieved both improvement in DIC and modest tumor shrinkage with the administration of nab-paclitaxel. 


\section{Case Reports in Oncology}

\section{Acknowledgements}

The authors would like to thank Dr. Bishal Gyawali, Nagoya University Hospital for his technical and linguistic assistance.

\section{Statement of Ethics}

Consent was obtained from the patient and her family for the publication of this case report.

\section{Disclosure Statement}

All authors have no conflicts of interest to disclose for this case report.

\section{References}

Young RJ, Brown NJ, Reed MW, Hughes D, Woll PJ: Angiosarcoma. Lancet Oncol 2010;11:983-991. Farid M, Ahn L, Brohl A, Cioffi A, Maki RG: Consumptive coagulopathy in angiosarcoma: a recurrent phenomenon? Sarcoma 2014;2014:617102.

-3 Alliot C, Tribout B, Barrios M, Gontier MF: Angiosarcoma variant of Kasabach-Merritt syndrome. Eur J Gastroenterol Hepatol 2001;13:731-734.

4 Bernathova M, Jaschke W, Pechlahner C, Zelger B, Bodner G: Primary angiosarcoma of the breast associated Kasabach-Merritt syndrome during pregnancy. Breast 2006;15:255-258.

-5 Fujisawa Y, Nakamura Y, Kawachi Y, Otsuka F: Docetaxel was effective in the management of metastatic angiosarcoma associated with disseminated intravascular coagulation syndrome. Int J Dermatol 2014;53:e138-e140.

6 Habringer S, Boekstegers A, Weiss L, Hopfinger G, Meissnitzer T, Melchardt T, et al: Kasabach-Merritt phenomenon in hepatic angiosarcoma. Br J Haematol 2014;167:716-718. Poroi Y, Furue M: Kasabach-Merritt syndrome associated with angiosarcoma of the scalp successfully treated with chemoradiotherapy. Acta Derm Venereol 2008;88:193-194. Lespi PJ, Alvarez GR, Iannariello MB, Wisnowski C: Hepatic angiosarcoma with disseminated intravascular coagulation. Medicina (B Aires) 1997;57:587-590. Maeda T, Uchino K, Otani T, Ueda Y: Cutaneous angiosarcoma with difficulty in differential diagnosis of thrombocytopenia. Rinsho Ketsueki 2010;51:402-406.

10 Massarweh S, Munis A, Karabakhtsian R, Romond E, Moss J: Metastatic angiosarcoma and KasabachMerritt syndrome. Rare Tumors 2014;6:5366.

11 Mazharuddin S, Podduturi V, Guileyardo JM, Cooper B: Hepatic angiosarcoma associated with disseminated intravascular coagulation. Proc (Bayl Univ Med Cent) 2015;28:54-56. Mazzocchi A, Foschini MP, Marconi F, Eusebi V: Kasabach-Merritt syndrome associated to angiosarcoma of the breast. A case report and review of the literature. Tumori 1993;79:137-140.

13 Moussa SH, Oliveira AL, de Amorim AP, Scandiuzzi D, Murta EF, Soares S: Angiosarcoma of the breast associated with Kasabach-Merritt syndrome. Arch Gynecol Obstet 2002;267:43-45.

14 Read WL, Williams F: Metastatic angiosarcoma with Kasabach-Merritt syndrome responsive to gemcitabine and vinorelbine after failure of liposomal doxorubicin and paclitaxel: a case report. Case Rep Oncol 2016;9:177-181.

15 Tan SM, Tay YK, Liu TT, Mancer K: Cutaneous angiosarcoma associated with the Kasabach-Merritt syndrome. Ann Acad Med Singapore 2010;39:941-942. 


\section{Case Reports in Oncology}

Honda et al:: Successful Treatment of Cardiac Angiosarcoma Associated with

Disseminated Intravascular Coagulation with Nab-Paclitaxel

16 Tordjman R, Eugene C, Clouet O, Wesenfelder L, Collet C, Bergue A: Hepatosplenic angiosarcoma complicated by hemoperitoneum and disseminated intravascular coagulation. Treatment by arterial embolization and chemotherapy. Gastroenterol Clin Biol 1995;19:625-628.

17 Wen S, Zhang W, Yang Y, Sun J: Angiosarcoma of the scalp and face associated with Kasabach-Merritt syndrome and disseminated intravascular coagulation. Indian J Dermatol Venereol Leprol 2016;82:9697.

18 Hara N, Fujimoto N, Miyamoto Y, Yamagishi T, Asano M, Fuchimoto Y, et al: Angiosarcoma of the thoracic wall responded well to nanoparticle albumin-bound paclitaxel: a case report. Drug Discov Ther 2016;10:114-116.

19 Olawaiye AB, Morgan JA, Goodman A, Fuller AF Jr, Penson RT: Epithelioid angiosarcoma of the uterus: a review of management. Arch Gynecol Obstet 2008;278:401-404.

-20 Croteau SE, Liang MG, Kozakewich HP, Alomari AI, Fishman SJ, Mulliken JB, et al: Kaposiform hemangioendothelioma: atypical features and risks of Kasabach-Merritt phenomenon in 107 referrals. J Pediatr 2013;162:142-147.

21 Kelly M: Kasabach-Merritt phenomenon. Pediatr Clin North Am 2010;57:1085-1089.
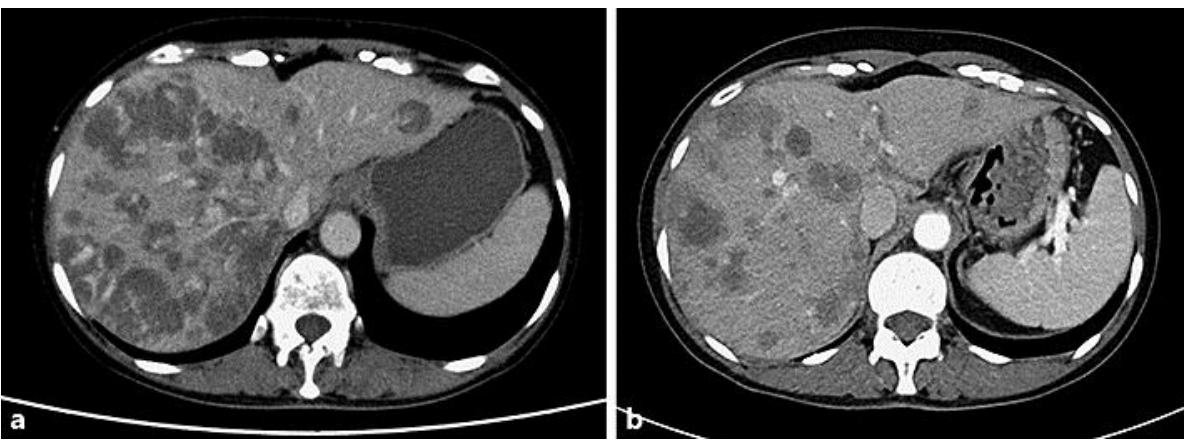

Fig. 1. CT evaluation before (a) and after (b) the start of chemotherapy. 


\section{Case Reports in Oncology}

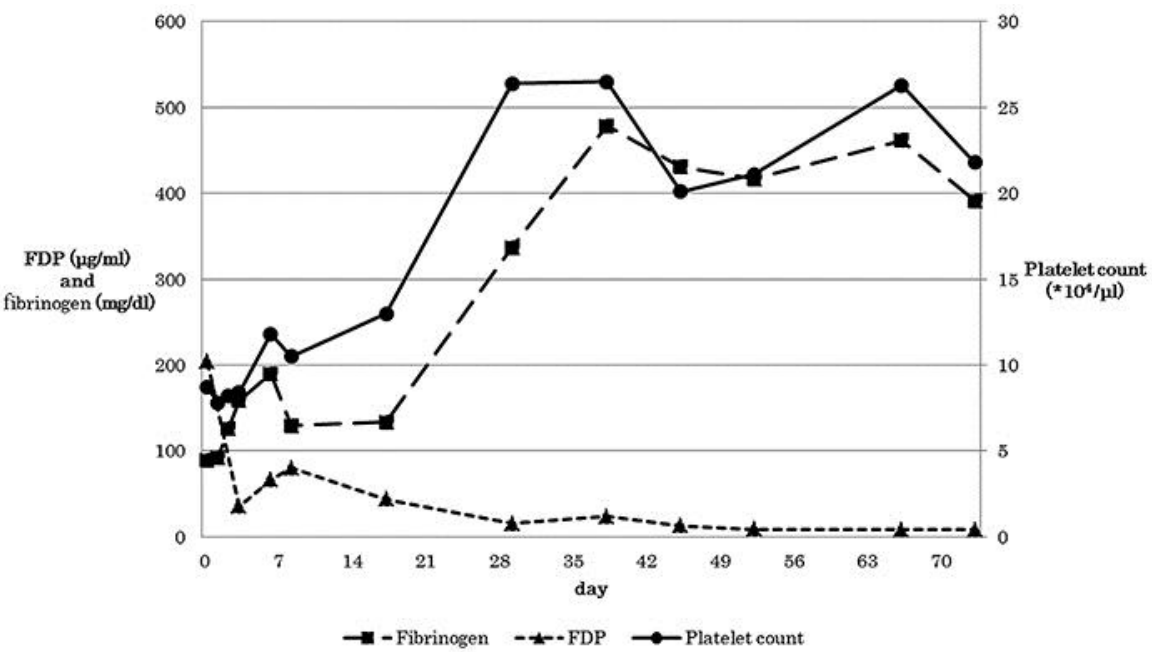

Fig. 2. Changes in platelet count and coagulation parameters during treatment. Closed squares, closed triangles, and closed circles describe fibrinogen, FDP, and platelet counts, respectively. Day 0 was the day on which the patient was referred to our hospital.

Honda et al.: Successful Treatment of Cardiac Angiosarcoma Associated with

Disseminated Intravascular Coagulation with Nab-Paclitaxel 


\section{Case Reports in Oncology}

Table 1. Literature review of patients with angiosarcoma complicated with DIC

\begin{tabular}{|c|c|c|c|c|}
\hline Case & First author [ref.] & Primary site & Treatment & Survival \\
\hline 1 & Alliot [3] & liver & - & 3 months \\
\hline 2 & Bernathova [4] & breast & C (unknown), S & alive \\
\hline 3 & Farid [2] & liver & C (liposomal doxorubicin) & 9 months \\
\hline 4 & & breast & $\begin{array}{l}\text { C (liposomal doxorubicin, carboplatin, } \\
\text { sirolimus, pazopanib, nab-paclitaxel, } \\
\text { bevacizumab, and vinorelbine) }\end{array}$ & 11 months \\
\hline 5 & & mediastinal & $\begin{array}{l}\text { C (doxorubicin, paclitaxel, ifosfamide, } \\
\text { cisplatin, gemcitabine, and vinorelbine) }\end{array}$ & 5 months \\
\hline 6 & & heart & C (doxorubicin and ifosfamide) & 6 months \\
\hline 7 & & breast & C (doxorubicin and ifosfamide) & 11 months \\
\hline 8 & & skull, meninges & - & 1 month \\
\hline 9 & & foot (bony) & - & 2 months \\
\hline 10 & Fujisawa [5] & spleen & C (docetaxel and paclitaxel) & alive \\
\hline 11 & Habringer [6] & liver & - & - \\
\hline 12 & Imafuku [7] & scalp & $\mathrm{C}$ (docetaxel), $\mathrm{R}$ & $\begin{array}{l}\text { alive }(>36 \\
\text { months) }\end{array}$ \\
\hline 13 & Lespi [8] & liver & - & - \\
\hline 14 & Maeda [9] & scalp & - & - \\
\hline 15 & Massarweh [10] & scalp & - & - \\
\hline 16 & Mazharuddin [11] & liver & - & - \\
\hline 17 & Mazzocchi [12] & breast & $\mathrm{S}$ & 8 years \\
\hline 18 & Moussa [13] & breast & - & - \\
\hline 19 & Read [14] & scalp & $\begin{array}{l}\text { C (paclitaxel, liposomal doxorubicin, } \\
\text { gemcitabine, and vinorelbine) }\end{array}$ & - \\
\hline 20 & Tan [15] & scalp & $\mathrm{R}$ & - \\
\hline 21 & Tordjman [16] & liver or spleen & C (unknown) & 15 months \\
\hline 22 & Wen [17] & scalp & - & - \\
\hline
\end{tabular}

C, chemotherapy; S, surgery; R, radiation. 